\title{
Terrorism, Radicalization and Psychiatry
}

Ana Sofia Machado ${ }^{1}$

Rosa Grangeia ${ }^{1}$

1. Psychiatry Service of São João University Hospital Center, Porto, Portugal

$\triangle$ anasofiamm7@gmail.com

In recent years, we have witnessed an increase in political, religious and ideological violence throughout the world.

The governmental entities have defined policies to combat this phenomenon establishing a role of mental health services in the identification of individuals at risk of radicalization.

The scientific body on psychological phenomena associated with terrorism is scanty and paved with methodological inaccuracies (1).

\section{Difficulties in studying Terrorism}

Definition and characterization of terrorism and related processes

Individual vs Groupal factors

Logistic and ethical limitations in interviewing people who commit terrorist acts

Suicide attacks

In the absence of determinant factors, the investigation has been directed to the path to radicalization with the emergence of models like the staircase model, NYPD fourstage model and cyclical complexity model $(5,6,7)$
We aim to review the relationship between terrorism, radicalization and mental illness in order to clarify the role of psychiatry, especially its forensic subspecialty, in this type of violence.

Literature review was based on PubMed/MEDLINE, using the keywords "psychiatry", "terrorism" and "radicalization".

\section{Terrorism Groups}

Directed, planned

Heterogeneity, no specific profile

No evidence of association to psychopatology $(3,3 \%)$ $(3,4)$
Lone-actors

Tendentially impulsive Associated to personality characteristics

Greater prevalence of psychopatology ( $32 \%)$ $(3,4)$
There is no evidence of an association between mental pathology and radicalization, but there is a greater prevalence of psychopathology in solitary terrorists $(2,3)$

\section{Psychiatry role}

\section{Old latent tension between the criminalization of ilness and psychiatrization of crime (8)}

Mental Health Services involved in Anti-terrorism Programs signaling and surveilance, no guidelines

\section{Divergent opinions in mental health professionals}

Marazzitti - psychiatry's interest in all manifestations of evil (9) Rahman T. - Terrorism motivated by extreme overvalued beliefs (10)

Prats et al - Role in desradicalization (11)

Royal College of Psychiatrists - no role in modifying extreme beliefs (12)

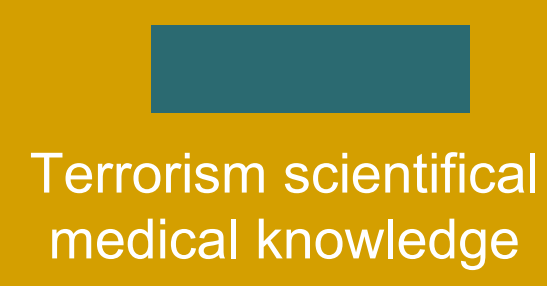
medical knowledge

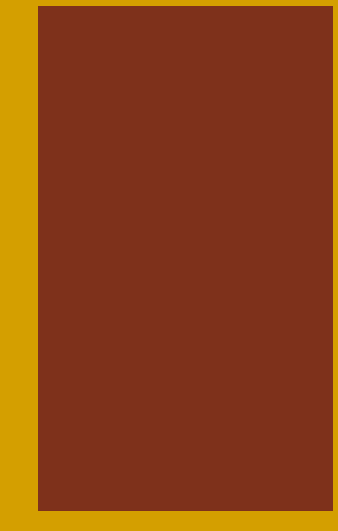

Anti-terrorism policies ( esp. involving mental health services)

Counterterrorism policies are not in line with scientific knowledge and can contribute to increased isolation and discrimination, requiring a breach of confidentiality that would make it impossible to establish a therapeutic relationship.

Psychiatrists working in a medical-legal context are in a unique position to study terrorism and radicalization, however, their evaluation in this specific type of violence needs to be cautiously individualized.

The role of psychiatry should not involve evaluation of radicalization risk or the adoption of techniques to promote the reverse process, but the treatment of mental disturbances associated with terrorism perpetrators and victims, deconstructing stigma and avoiding discrimination.
Terrorism is a form of violent behavior that deserves to be studied by the behavioral sciences with urgent refinement of research methods, with psychometric assessment and a better characterization of the stages of the process from exposure to the adoption of extremist thinking, subjugation to radicalist forces, connection with terrorist group until the execution of a terrorist act.

The type of connection to terrorism with violent progression vs. nonviolent, the particularization of the role within the group and its link (or not) to mental illness are other necessary areas of study. 